\title{
CONCENTRATIONS OF SELECTED TOXIC ELEMENTS IN AIRBORNE PARTICULATES OF PATRAS, GREECE
}

\author{
A.A. BLOUTSOS \\ P.C. YANNOPOULOS ${ }^{\star}$
}

\author{
Environmental Engineering Laboratory, Department of Civil \\ Engineering, University of Patras \\ 26504 Patras, Greece
}

Received: 03/08/10

Accepted: 10/03/11 *to whom all correspondence should be addressed: e-mail: p.c.yannopoulos@upatras.gr

\begin{abstract}
The $\mathrm{Mn}$ and $\mathrm{Pb}$ of the total suspended particulates (TSP) in totally 95 1-h samples and As, Cd, Mn, $\mathrm{Ni}$ and $\mathrm{Pb}$ in totally 29 24-h samples have been determined by flameless graphite furnace atomic absorption spectrophotometry. The monthly TSP for July 1992 contained Mn and $\mathrm{Pb} 0.033$ and $1.25 \%$ in downtown Patras and 0.029 and $1.50 \%$ at the University Campus, correspondingly. The corresponding As, Cd, Mn, Ni and Pb contents for October 1992 were 0.060, 0.0038, 0.079, 0.087 and $1.67 \%$ in downtown Patras and $0.534,0.0087,0.012,0.204$ and $0.68 \%$ at the University Campus. Only As monthly levels had exceeded the European Air Quality Standard of $6 \mathrm{ng} \mathrm{m}^{-3}$. Toxic element proportions have weak correlations to traffic. Patras data showed Pb levels $0.216 \pm 0.115 \mu \mathrm{g}$ $\mathrm{m}^{-3}$, smaller than other Greek cities, following expected decay rate. Factor analysis has detected three factors explaining more than $85.0 \%$ of variance: 1 . Mostly correlated to $\mathrm{Pb}, \mathrm{Cd}$ and $\mathrm{Ni}$, pointing out road and harbour traffic; 2 . mostly correlated to Mn and TSP, indicating central heating, ship emissions, soil re-suspension and background contributions; and 3. mostly correlated to As (Spearman correlation also shows it), denoting spray disinfections. The lack of data for Patras, especially for As, makes present findings historically useful, as they entail more systematic monitoring nowadays and could be valuable for epidemiological and environmental assessment studies.
\end{abstract}

KEYWORDS: Air pollution; Factor analysis; Flameless Atomic Absorption Spectrometry; Heavy metals; Lead, Nickel, Manganese and Cadmium in TSP; Urban/Suburban.

\section{INTRODUCTION}

Patras is the third largest city of Greece with population 167,602 (2001 census), which is increased during summertime, festivals and workdays. Patras air pollution, regarding total suspended particulates (TSP), originates from sources, as harbour, traffic and central heating, commonly found in Mediterranean cities (Yannopoulos and Skokaki, 2003; Yannopoulos, 2008). The toxic elements, $\mathrm{As}, \mathrm{Cd}, \mathrm{Mn}, \mathrm{Ni}$ and $\mathrm{Pb}$ studied herein, are contained in airborne particulates coming mostly from anthropogenic activities and natural sources (EEA, 2003).

The major source of human exposure to As is food. It may have severe acute and/or chronic symptoms (Cope et al., 2004). The population exposure to $\mathrm{Cd}$ is made via food and tobacco smoking and there is sufficient evidence that $\mathrm{Cd}$ and its compounds can produce lung cancer in humans and animals exposed by inhalation. $\mathrm{Cd}$ and $\mathrm{Cd}$ compounds has been classified as Group 1 human carcinogens (IARC, 1993). The toxicity of Mn varies according to the route of exposure, but it has not been adequately investigated. Regarding Mn human carcinogenicity, United States (US) Environmental Protection Agency (EPA) has not classified Mn as carcinogenic (WHO, 2000; 2004). Exposure to $\mathrm{Ni}$ and $\mathrm{Ni}$ compounds is via food, water and smoking and increases lung and nasal cancer risks (US EPA, 1999). The main route of population exposure to $\mathrm{Pb}$ is via air $\mathrm{Pb}$ content, but $\mathrm{Pb}$ in dust also contributes to an increase Pb uptake (Mugica et al., 2002; Siskos et al., 2001). 
The present work provides the earliest Patras air quality regarding $\mathrm{As}, \mathrm{Cd}, \mathrm{Mn}, \mathrm{Ni}$ and $\mathrm{Pb}$ levels at a most critical downtown location and a suburban location. Exempting some early data on $\mathrm{Pb}$ levels published (Skokaki and Yannopoulos, 2006), early information for As, Cd, Mn and Ni concentration levels is completely missed. Moreover, the present work presents additional data and examines associated correlations among all aforementioned toxicants.

\section{METHODOLOGY OF SAMPLING AND ANALYSIS Sampling procedure}

The present study presents the analysis of Programs 2 and 4 conducted in 1992 by the Environmental Engineering Laboratory (EEL) of the Department of Civil Engineering of the University of Patras, using high volume air samplers, and compares data to the corresponding data available in the literature. The EEL Program 2 included 87 1-h sampling runs at Location A1 on the Vas. Georgiou A' Square in downtown Patras with period of sampling from July 1 to 31 and 8 1-h sampling runs at Location C1 near the EEL premises on the University of Patras Campus with dates of sampling on June $23,24,25,29$ and July 27 . The detailed diary of the sampling program is given in Table 1. EEL Program 4 included 27 24-h sampling runs at Location A on the Vas. Georgiou A' Square with period of sampling from October 4 to 31 and 2 24-h sampling runs at Location C1 with dates of sampling on October 3 and November 1. The typical start time of sampling was at noon, 12:00. Soon after sampling and TSP determination, the filters enclosed in aluminium foil envelops and shielded into poly-bags entirely empty of air have been preserved in a dark place of room temperature. Later on, portions of the filters of EEL Program 2 have been analysed for $\mathrm{Pb}$, and $\mathrm{Mn}$ contents and portions of the filters of EEL Program 4 have been analysed for $\mathrm{As}, \mathrm{Cd}, \mathrm{Mn}, \mathrm{Ni}$ and $\mathrm{Pb}$ contents. Sampling and analysis for the determination of the TSP matter were conducted according to the Hellenic Standard "ELOT 713" (gravimetric method) of the Greek Standardization Organization. For both EEL Programs, the sampler flow rate, sampling duration, ambient temperature, weather and shopping conditions, as well as traffic rates were recorded. For EEL Program 2 recordings were made in the beginning and at the end of the 1-h sampling runs, while for EEL Program 4, which concerns in 24-h sampling runs, at intervals approximately equal to three hours. Specific details of sampling and analysis can be found in (Yannopoulos and Skokaki, 2003; Yannopoulos, 2008). Each filter was pre- and post-weighed after remaining in a desiccator containing magnesium perchlorate to stabilise humidity level to $50 \%$ for at least 24 hours. Filter's marginal (unexposed) section was removed. After final weighing, the mean proportion of the exposed area to the total filter area was determined and was $89.89 \%$ and $92.82 \%$, for 4 -in. and $8 \times 10$-in. size filters, respectively.

Table 1. Sampling dates of the EEL Program 2 for Locations A1 and C1

\begin{tabular}{llllllll}
\hline $\begin{array}{l}\text { Typical start time } \\
\text { of sampling }\end{array}$ & $\mathrm{M}$ & $\mathrm{T}$ & $\mathrm{W}$ & $\mathrm{T}$ & $\mathrm{F}$ & $\mathrm{S}$ & $\mathrm{S}$ \\
\hline $\begin{array}{l}\text { Location A1: Vas. } \\
\text { 03:00 }\end{array}$ & 6 & 7 & 15 & 2 & 3 & 4 & 5 \\
$08: 00$ & 13,20 & $14,21,28$ & $1,15,29$ & $2,9,30$ & 3,17 & 4,18 & 12,19 \\
$12: 00$ & 13,20 & 14,21 & 1,15 & 2,9 & $10,17,31$ & 4,11 & $5,12,26$ \\
$15: 30$ & 13,20 & 7,21 & 1,8 & 2,16 & $3,10,24$ & 4,18 & 5,19 \\
$19: 30$ & 6,13 & 7,14 & $1,8,22$ & 2,16 & 3,10 & 4,11 & 5,12 \\
$22: 00$ & 6,13 & 7,14 & $1,8,29$ & $2,9,23$ & $10,17,24$ & 4,11 & 5,12 \\
\hline
\end{tabular}

Location C1: University of Patras Campus, 1992

June 23, Tuesday 13:30; June 24, Wednesday 09:00 \& 10:50; June 25, Thursday 09:10 \& 12:10; June 29, Monday 12:45; July27, Monday 14:15 \& 17:30

Exposed circles of each glass fibre filter 3.8-in. $(9.7-\mathrm{cm})$ in diameter are divided into 8 equal sectors and exposed rectangles $7.7 \times 9.7$-in. $(19.5 \times 24.6-\mathrm{cm} \times \mathrm{cm})$ in size are divided into 16 equal straps. They are all cut with a surgery-blade cutter. Regarding EEL Program 2, one sector from the 8 sectors of each filter sampled on each hour has been used to determine the hourly average mass of a toxicant pollutant, while regarding EEL Program 4 the daily average mass is determined using the two straps from the 16 straps of each filter sampled on each day. These filter parts were chopped 
and put in a 100-ml Teflon flask. Contents of each particular flask were treated separately applying the digestion and measurement process. The toxic element concentrations in air were calculated by applying the measured element content in TSP mass to the total TSP mass sampled during a prescribed period.

The filter ash digestion process followed for $\mathrm{Cd}, \mathrm{Mn}, \mathrm{Ni}$ and $\mathrm{Pb}$ contents was similar to that proposed by APHA (1977) in chapters 311, 316, 320 and 315, concerning the corresponding tentative methods of analysis of atmospheric particulate matter by atomic absorption spectroscopy. For the filter ash digestion for As determination, a process similar to $\mathrm{Cd}$ is followed. In the analysis reagents of Merck \& Co., Inc. were used: Suprapur (distilled, deionised) water, concentrated nitric acid (65.3\%) suprapur, concentrated perchloric acid (70.5\%) suprapur and concentrated hydrochloric acid (31 or $32.8 \%$ ) ultrapur. A 40-ml mixture 2:1 of nitric and perchloric acid was added to each Teflon flask, where each sample of filter was put as well. For both EEL Programs, each sample remained for 36 hours for ashing of filter mass and, then, the mixture put in 100-ml Erlenmeyer flask was boiled in a closed-loop device for two hours. After the dilution in the flask has obtained room temperature, the flask walls were rinsed with small quantities of distilled water and the dilution was boiled again for one hour using the same device. After obtaining room temperature, samples were filtered using fibreglass filters to remove suspended particulate matter. $10 \mathrm{ml}$ of each sample put in a 25-ml Propylene cylinder, where $1.2 \mathrm{ml} \mathrm{HCl} \mathrm{1:1} \mathrm{added.} \mathrm{The} \mathrm{mixture} \mathrm{put} \mathrm{in} \mathrm{a} \mathrm{100-ml} \mathrm{Teflon} \mathrm{flask} \mathrm{was}$ diluted using $\mathrm{HCl}$ 1:10 up to a final volume of $50 \mathrm{ml}$ for the EEL Program 2 and $75 \mathrm{ml}$ for the EEL Program 4 and was ready for measurements. In the present study no addition of any matrix modifier solution was made (Niedzielski et al., 2002).

\section{Determination of concentrations}

Concentrations of the aforementioned toxic elements were determined using flameless atomic absorption spectrophotometry after filter digestion described above. The model 2280 Perkin-Elmer spectrophotometer equipped with an HGA-300 graphite furnace and a suitable hollow cathode lamp was used for all analytical measurements. Measurement checks were made by the method of standard additions. In general, equal volumes of well-mixed samples and working standard and blank were prepared in polystyrene cups. Working standards were prepared daily from As, $\mathrm{Cd}, \mathrm{Mn}$, $\mathrm{Ni}$ and $\mathrm{Pb}$ stock solutions of $1000 \mu \mathrm{g} \mathrm{L}{ }^{-1}$ each. Each sample was analysed five times in order to calculate an average value of absorption units, as most reliable. The linearity of the calibration curve was found satisfactory, since $r^{2}$ approaches unity, as shown in Table 2 . In the same table the characteristic concentration for $10-\mu \mathrm{l}$ or $20-\mu \mathrm{l}$ sample volume injected in the graphite furnace, the limit of detection (LOD), the wavelength and the slot width used were also given for each element measured. LOD was obtained as three times the mean standard deviation of the blanks. Literature values of LOD by electrothermal atomic absorption spectrometry for As in atmospheric aerosol are among 0.02 and $0.163 \mu \mathrm{g} \mathrm{L}^{-1}$, which are smaller than $5.26 \mu \mathrm{g} \mathrm{L}^{-1}$ succeeded by the present analysis. Literature values of LOD for $C d$ are in the range $0.02-0.131 \mathrm{\mu g} \mathrm{L}^{-1}$, which are of the same order with LOD determined herein $\left(0.057 \mu \mathrm{g} \mathrm{L}^{-1}\right)$. For $\mathrm{Pb}$ analysis, LOD values in the range 0.124-1.4 $\mu \mathrm{g} \mathrm{L}^{-1}$ has been given by Karanasiou et al. (2005) and Melaku et al. (2008), which are lower or approximately equal to the present value. The furnace programme settings for the EEL Programs 2 and 4 are given in Table 3.

Table 2. Characteristics of calibration standards for the EEL Programs 2 and 4

\begin{tabular}{|c|c|c|c|c|c|c|c|c|}
\hline Toxic & $\begin{array}{c}\text { Calibration } \\
\text { range } \\
\left(\mu \mathrm{g} \mathrm{L}^{-1}\right) \\
\end{array}$ & $\begin{array}{l}\text { Coefficient a } \\
\left(\mu \mathrm{g} \mathrm{L}^{-1} \mathrm{Abs}^{-1}\right)^{\star \star}\end{array}$ & $r^{2}$ & $\begin{array}{c}\text { LOD } \\
\left(\mu g \mathrm{~L}^{-1}\right)\end{array}$ & $\begin{array}{l}\text { Wavelength } \\
(\mathrm{nm})\end{array}$ & $\begin{array}{c}\text { Slot } \\
\text { width } \\
(\mathrm{nm})\end{array}$ & $\begin{array}{c}\text { Injected } \\
\text { volume } \\
(\mu \mathrm{L})\end{array}$ & $\begin{array}{c}\text { Characteristic } \\
\text { concentration } \\
\left(\mu \mathrm{g} \mathrm{L}^{-1}\right) \\
\end{array}$ \\
\hline As & $0-100$ & 219.36 & 0.9833 & 5.26 & 193.7 & 0.7 & 20 & 0.85 \\
\hline $\mathrm{Cd}$ & $0-2.5$ & 6.3742 & 0.9976 & 0.057 & 228.8 & 0.7 & 20 & 0.0175 \\
\hline $\mathrm{Mn}$ & $0-50(0-2500)^{*}$ & $22.547(33,604)$ & $0.9826(0.9894)$ & $0.27(403)$ & 279.5 & 0.2 & $20(10)$ & $0.11(0.22)$ \\
\hline $\mathrm{Ni}$ & $0-50$ & 382.95 & 0.9824 & 5.74 & 232.0 & 0.2 & 20 & 0.65 \\
\hline $\mathrm{Pb}$ & $0-250(0-100)$ & $274.25(188.13)$ & $0.9975(0.9854)$ & $1.65(1.13)$ & 283.3 & 0.7 & 10 & 1.2 \\
\hline
\end{tabular}

* For the analysis of EEL Program 2, differences are given in parentheses

${ }^{*}$ Abs is abbreviation of the absorbance measured by the spectrophotometer 
Table 3. Graphite furnace programme settings for the analyses of EEL Programs 2 and 4

\begin{tabular}{|c|c|c|c|c|c|}
\hline Operation settings & Drying & Charring & Atomisation & Cleaning & Purging \\
\hline \multicolumn{6}{|l|}{ As } \\
\hline Temperature $\left({ }^{\circ} \mathrm{C}\right)$ & $110-130-250$ & 1300 & 2300 & 2500 & 20 \\
\hline Ramp time (s) & $10-5-10$ & 6 & 1 & 1 & 2 \\
\hline Hold time (s) & $25-25-25$ & 5 & 6 & 3 & 2 \\
\hline \multicolumn{6}{|l|}{$\mathrm{Cd}$} \\
\hline Temperature $\left({ }^{\circ} \mathrm{C}\right)$ & 110 & 700 & 1600 & 1900 & 20 \\
\hline Ramp time (s) & 10 & 7 & 1 & 1 & 2 \\
\hline Hold time (s) & 25 & 10 & 6 & 3 & 2 \\
\hline \multicolumn{6}{|l|}{$\mathrm{Mn}$} \\
\hline Temperature $\left({ }^{\circ} \mathrm{C}\right)$ & 110 & $1400(1100)$ & $2200(1900)$ & $2400(2200)$ & 20 \\
\hline Ramp time (s) & $10(11)^{\star}$ & $6(4)$ & 1 & 1 & 2 \\
\hline Hold time (s) & $25(20)$ & 15 & $7(5)$ & $3(2)$ & 2 \\
\hline \multicolumn{6}{|l|}{$\mathrm{Ni}$} \\
\hline Temperature $\left({ }^{\circ} \mathrm{C}\right)$ & 130 & 1400 & 2500 & 2600 & 20 \\
\hline Ramp time (s) & 10 & 7 & 1 & 1 & 2 \\
\hline Hold time (s) & 25 & 20 & 6 & 2 & 2 \\
\hline \multicolumn{6}{|l|}{$\mathrm{Pb}$} \\
\hline Temperature $\left({ }^{\circ} \mathrm{C}\right)$ & 130 & 800 & 2000 & 2200 & 20 \\
\hline Ramp time (s) & 10 & 7 & 1 & 1 & 2 \\
\hline Hold time (s) & 20 & 15 & 6 & 2 & 2 \\
\hline
\end{tabular}

* For the analysis of EEL Program 2, differences are given in parentheses

\section{RESULTS AND DISCUSSION}

Monthly and yearly average concentration levels

The monthly average toxic element concentrations for EEL Program 2 and 4 were determined using the daily average concentrations for the days included in the month of sampling. The results of monthly average values plus/minus their standard deviations are given in Table 4 for both urban and suburban locations (Location A1 and Location C1). In the same Table the European Air Quality Standards for As, Cd, Ni and Pb concentrations, last updated on 30/04/2008, are given. Neither EPA nor the European Union (EU) has given any limit values for Mn. WHO (2000) have established the value of $150 \mathrm{ng} \mathrm{m}^{-3}$ as annual tolerance concentration. Only the monthly average As concentrations found greater than the yearly limit value, but the high variability between measurements makes doubtful to approximate the actual yearly average concentrations with the average of the corresponding monthly values. However, Patras population exposure to As levels approximately equal to or higher than the EU limit requires a more systematic monitoring. The monthly average Cd, $\mathrm{Mn}, \mathrm{Ni}$ and $\mathrm{Pb}$ concentrations were enough lower than the EU yearly limits. Available yearly average values for urban or suburban sites of Athens and Thessaloniki show comparable results, while Patras levels were found lower than at above suburban sites (Misaelides et al., 1993; Manoli et al., 2002; Voutsa et al., 2002; Thomaidis et al., 2003; Manalis et al., 2005; Karanasiou et al., 2007; Vasilakos et al., 2007a; and 2007b; Farmaki and Thomaidis, 2008; Melaku et al., 2008). The monthly $\mathrm{Mn}$ and Ni concentrations were lower than the annual levels measured in areas of northern Italy with industrial and agricultural activities (Braga Marcazzan, 1996; Marcazzan et al., 2002).

\section{Monthly average and typical week and diurnal variations}

The monthly average mass proportions expressed as the ratio (\%) of the toxic element mass over the TSP mass multiplied by 1000 is calculated and given in Table 5. These proportions are equivalent to the mass proportions expressed as the mass in $\mathrm{mg}$ of the toxic element over the mass in $\mathrm{g}$ of TSP. Present findings are in fair agreement to other measurements.

The daily average variations of the $\mathrm{Pb}$ and $\mathrm{Mn}$ mass proportions during a typical week of EEL Programs 2 and 4, as well as the diurnal variations during each day of week of EEL Program 2, are synoptically shown in Figures $1 \mathrm{a}$ through 1e, respectively, while in Figure 1f the typical patterns corresponding to traffic rates of Maizonos Str. at the site vicinity are given. None of these patterns has a good similarity to the pattern of traffic rates, indicating a weak correlation to traffic. A similar result is deduced by Figure 2 regarding diurnal patterns of Mn/TSP and Pb/TSP. The high values of $\mathrm{Mn} / \mathrm{TSP}$ observed in the night (03:00), when traffic rates are minimised, indicate that Mn source is 
other than traffic; maybe the harbour and probable nearby industrial activities as explaned by Skokaki and Yannopoulos (2006).

Table 4. Monthly average concentrations of $\mathrm{As}, \mathrm{Cd}, \mathrm{Mn}, \mathrm{Ni}$ and $\mathrm{Pb}$ with their standard deviations for EEL Program 2 and 4, as well as the European Air Quality Standards

\begin{tabular}{|c|c|c|c|c|c|}
\hline Location & As $\left(\mathrm{ng} \mathrm{m}^{-3}\right)$ & $\mathrm{Cd}\left(\mathrm{ng} \mathrm{m}^{-3}\right)$ & $\mathrm{Mn}\left(\mathrm{ng} \mathrm{m}^{-3}\right)$ & $\mathrm{Ni}\left(\mathrm{ng} \mathrm{m}^{-3}\right)$ & $\mathrm{Pb}\left(\mathrm{ng} \mathrm{m}^{-3}\right)$ \\
\hline \multicolumn{6}{|c|}{ EEL Program 2 (July 1992) } \\
\hline A1 & & & $3.9 \pm 0.5$ & & $148 \pm 28$ \\
\hline C1 & & & $2.2 \pm 3.0$ & & $113 \pm 78$ \\
\hline \multicolumn{6}{|c|}{ EEL Program 4 (October 1992) } \\
\hline A1 & $8.6 \pm 13.5$ & $0.61 \pm 0.45$ & $14.7 \pm 8.8$ & $15.9 \pm 20.1$ & $295 \pm 128$ \\
\hline C1 & $14.9 \pm 21.1$ & $0.33 \pm 0.09$ & $0.6 \pm 0.9$ & $7.4 \pm 0.2$ & $27 \pm 11$ \\
\hline \multicolumn{6}{|c|}{ European Air Quality Standards (for 1-y averaging period) } \\
\hline & $6^{*}$ & $5^{\star}$ & $20^{*}$ & $0.5^{\star \star}$ & $1.0^{\star \star \star}$ \\
\hline
\end{tabular}

* Target value enters into force 1.1.2012

** Target value enters into force 1.1.2005 or 1.1.2010 in the immediate vicinity of specific, notified industrial sources

$\star \star \star$ Limit value applies from 1.1.2005 to 31.12.2009

Table 5. Monthly average toxic element/TSP mass proportions (\%) for EEL Program 2 and 4

\begin{tabular}{|c|c|c|c|c|c|}
\hline Description & As/TSP & $\mathrm{Cd} / \mathrm{TSP}$ & $\mathrm{Mn} / \mathrm{TSP}$ & $\mathrm{Ni} / \mathrm{TSP} *$ & $\mathrm{~Pb} / \mathrm{TSP} *$ \\
\hline \multicolumn{6}{|l|}{ EEL Program 2 (July 1992) } \\
\hline A1 & & & 0.033 & & 1.25 \\
\hline C1 & & & 0.029 & & 1.50 \\
\hline \multicolumn{6}{|l|}{ EEL Program 4 (October 1992) } \\
\hline A1 & 0.060 & 0.0038 & 0.079 & 0.087 & 1.67 \\
\hline C1 & 0.534 & 0.0087 & 0.012 & 0.204 & 0.68 \\
\hline \multicolumn{6}{|l|}{ Other measurements } \\
\hline A1 (Skokaki and Yannopoulos, 2006) & & & & & 2.00 \\
\hline C1 (Skokaki and Yannopoulos, 2006) & & & & & 0.26 \\
\hline $\begin{array}{l}\text { Urban air in Athens centre (Valavanidis } \\
\text { et al., 2006) }\end{array}$ & & $0.0045-0.0058$ & & $0.302-0.350$ & $2.70-2.90$ \\
\hline $\begin{array}{l}\text { Industrial and agricultural sites in } \\
\text { Northern Italy (Braga Marcazzan, 1996) }\end{array}$ & & & $0.333-1.55$ & $0.071-0.225$ & $1.33-7.53$ \\
\hline
\end{tabular}

* Note that at Akrotiri of Crete Kopanakis et al. (2010) found $\mathrm{Pb}$ and Ni proportions (\%) in $\mathrm{PM}_{10}$ equal to 1.72 and 0.047.

Given the daily average values of the toxic element proportions for a typical week (Figure 1), as well as the daily average TSP concentrations (Yannopoulos, 2008), the daily average toxic element levels of $\mathrm{Mn}$ and $\mathrm{Pb}$ for EEL Program 2 and of $\mathrm{As}, \mathrm{Cd}, \mathrm{Mn}, \mathrm{Ni}$ and $\mathrm{Pb}$ for EEL Program 4 have been computed and shown in Figure 3, for Location A1 in downtown Patras. The levels of $\mathrm{Mn}$ had the smallest fluctuations during the typical week, while the levels of As presented the highest fluctuations. Moderate fluctuations are shown for $\mathrm{Cd}$, Ni and Pb. From the Mn/TSP and Pb/TSP proportions determined for the days of the typical week of July 1992 and for prescribed hour of day, as well as the TSP concentrations corresponding to these days, the diurnal Mn and Pb levels have been calculated and shown in Figures $2 \mathrm{~d}$ and $2 \mathrm{e}$. A loud difference between $\mathrm{Mn}$ and $\mathrm{Pb}$ levels is that for some days of week Mn presents higher levels during night (03:00) hours than the rest hours of the day, while $\mathrm{Pb}$ at 03:00 gets rather smaller levels. This is expected since $\mathrm{Pb}$ source is the leaded fuel. It is not known any industrial source of $\mathrm{Mn}$ in the neighbourhood of the Location A1. Therefore, contributions from harbour, re-suspended particulate matter and background air pollution may justify the aforementioned $\mathrm{Mn}$ behaviour.

\section{Long-term variation of lead levels}

Due to the lack of long-term $\mathrm{Pb}$ measurements in Patras, since $\mathrm{Pb}$ levels in air depend on emissions mainly due to combustion of leaded petrol, it is adopted that $\mathrm{Pb}$ levels would present a long-term decay proportional to the evolution of leaded petrol in Greece (HMEPPPW, 2006). The evolution of leaded petrol in the period 1991-2002 is shown in Figure 4. Grey line accompanied with the grey axis (right) correspond to the evolution in Attika Prefecture and the black line accompanied with the black axis (right) to the evolution in Greece in general. Patras data for July and October 1992 show 
that $\mathrm{Pb}$ decay rate has got the levels corresponding $0.148 \pm 0.028$ and $0.295 \pm 0.128 \mu \mathrm{g} \mathrm{m}^{-3}$, which are smaller levels than other Greek cities (Athens, Piraeus and Thessaloniki) (HMEPPPW, 2005; MMT, 1997-2001) and rather follow the decay rate for Greece excluding Attika, as expected. According to Figure 4, the $\mathrm{Pb}$ long-term variation for Patras may be estimated by the thick line.
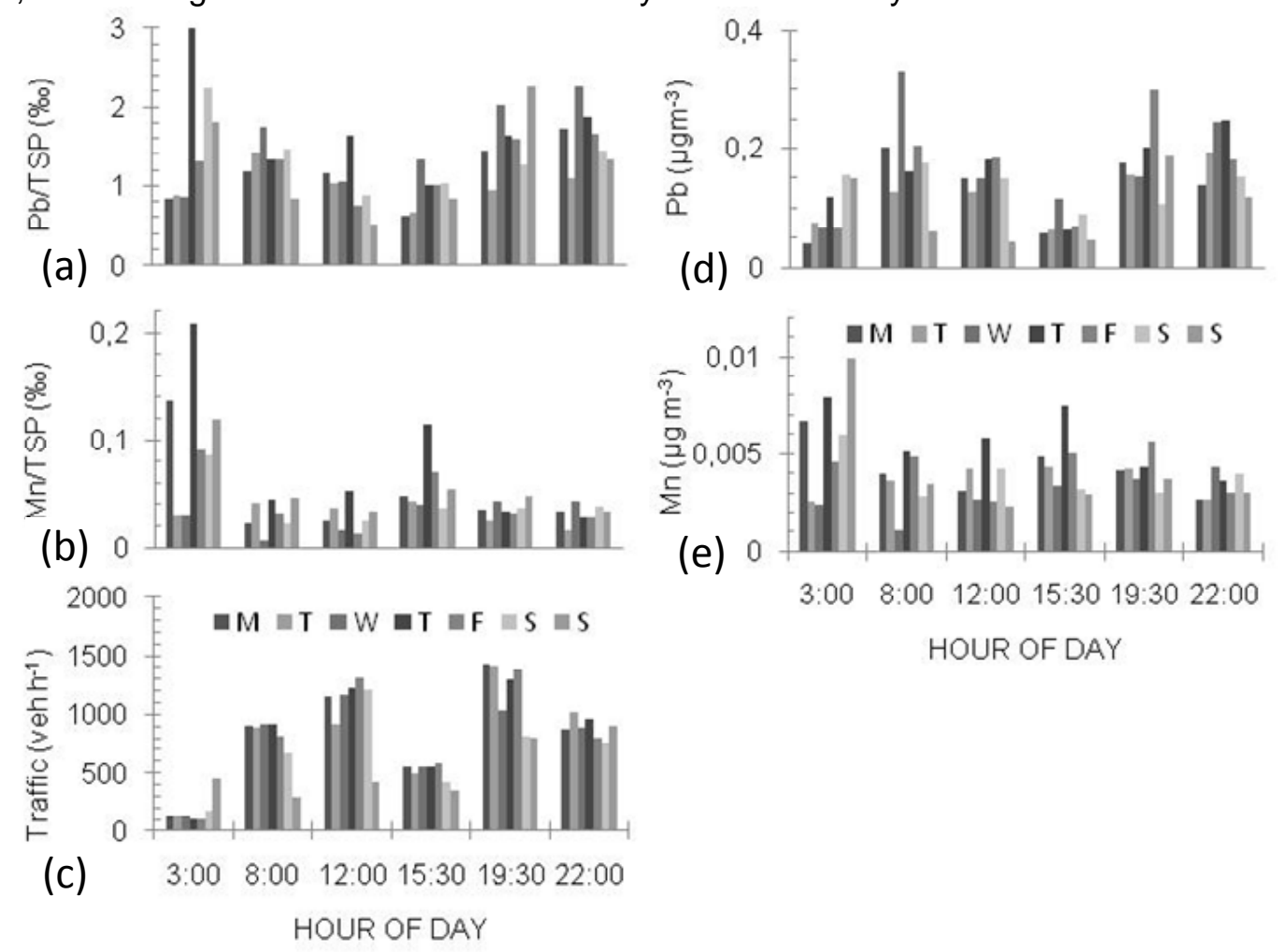

HOUR OF DAY

Figure 1. Variation of toxic element proportions (\%) during a typical week
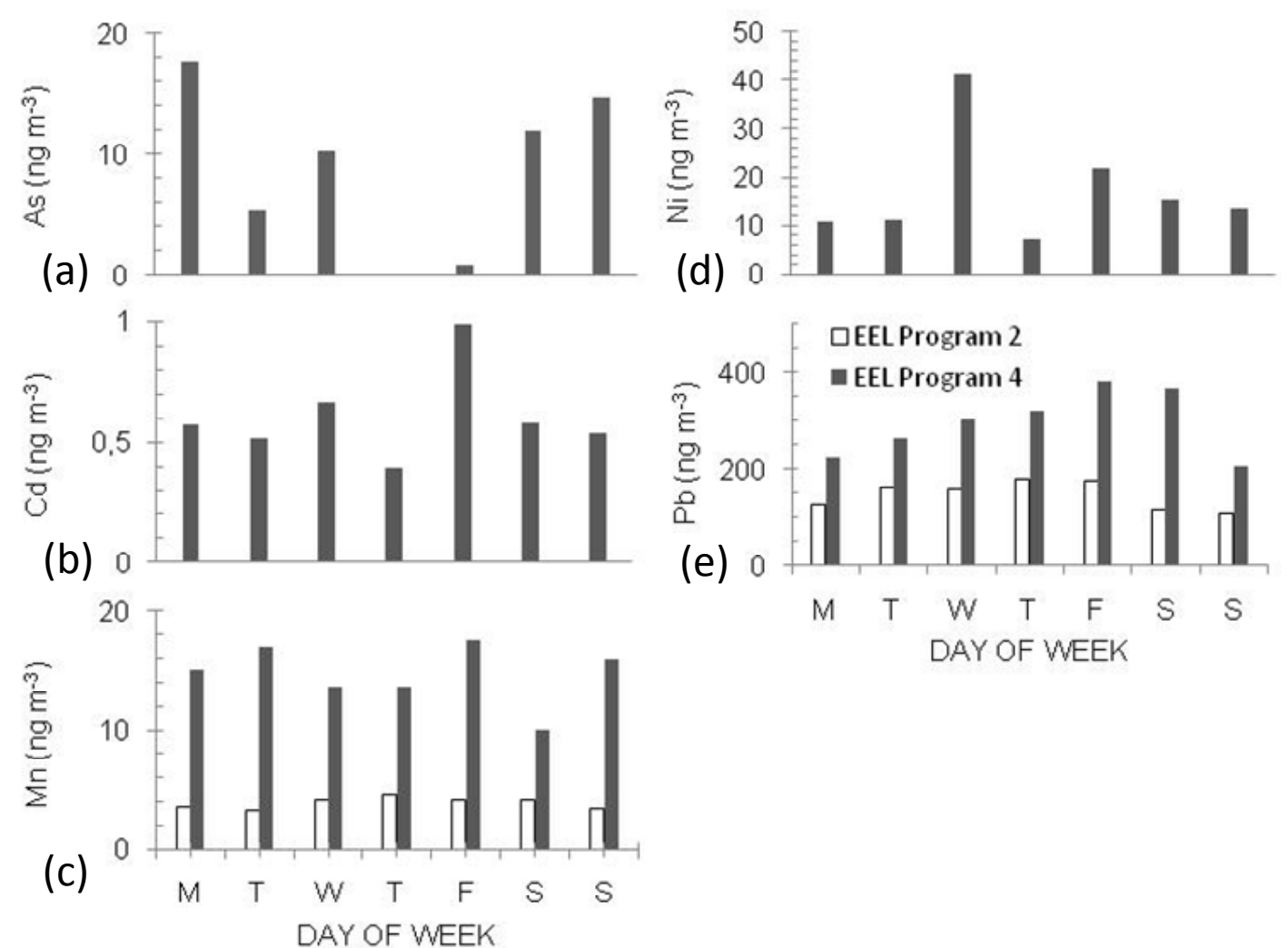

Figure 2. Diurnal variation of $\mathrm{Pb}$ and $\mathrm{Mn}$ proportions (a), (b), (c) and of hourly mean concentrations ( $\left.\mathrm{ng} \mathrm{m}^{-3}\right)(\mathrm{d})$ and $(\mathrm{e})$ 

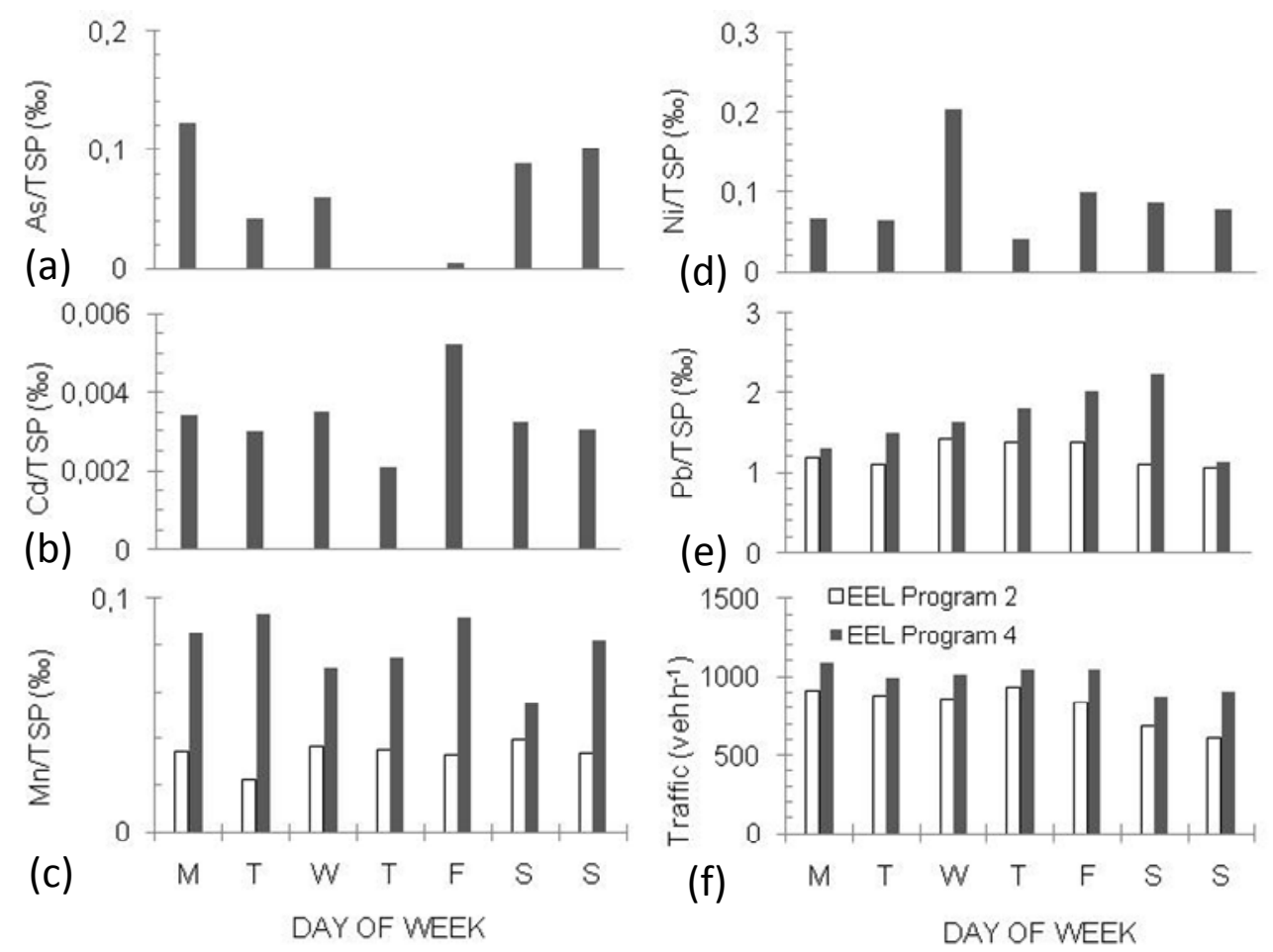

Figure 3. Weekly variation of daily average concentrations $\left(\mathrm{ng} \mathrm{m}^{-3}\right)$

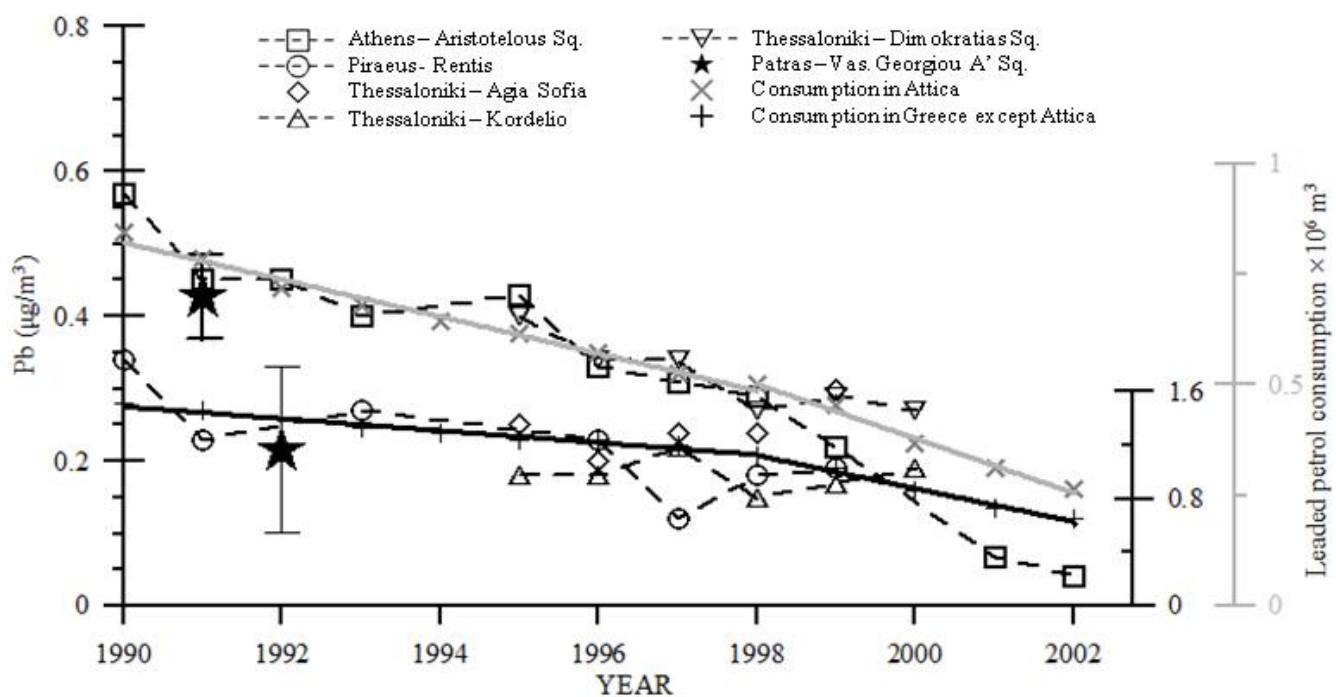

Figure 4. Predicted long-term variation of $\mathrm{Pb}$ levels at Patras Location $\mathrm{A} 1$ (thick line) assumed proportional to the decay of leaded petrol consumption in Greece (open symbols) and verification with measurements in Patras, Athens, Piraeus and Thessaloniki

For the year 2002 and later on, the above method predicts less than $0.12 \mu \mathrm{g} \mathrm{m}^{-3} \mathrm{~Pb}$ level at Location A1 (Skokaki and Yannopoulos, 2006). The proposed method is validated by available data for urban areas of Athens, Piraeus and Thessaloniki. An overall assessment of the Pb levels at Location A1 in downtown Patras implies that they were quite lower than $0.5 \mu \mathrm{g} \mathrm{m}^{-3}$ limit value and should be continued to.

\section{Spearman correlations and factor analysis}

Data of the EEL Program 4 have been used by the SPSS software to perform a factor analysis and calculate Spearman correlation coefficients given in Table 6. In hierarchical order, (Cd, Ni), (TSP, $\mathrm{Mn}),(\mathrm{Cd}, \mathrm{Mn})$ and $(\mathrm{As}, \mathrm{Ni})$ give the highest coefficients (0.791 to 0.565$)$ at 0.01 significance level (2tailed), while (Mn, $\mathrm{Pb}$ ), (Cd, Pb), (Mn, Ni), (TSP, Pb) and (As, Cd) follow (0.453 to 0.429) and (TSP, As) shows negative coefficient (-0.465) at 0.05 significance level (2-tailed). 
Table 6. Spearman correlation coefficients for pair-wise comparison between TSP concentrations and trace elements

\begin{tabular}{ccccccc}
\hline & TSP & As & $\mathrm{Cd}$ & $\mathrm{Mn}$ & $\mathrm{Ni}$ & $\mathrm{Pb}$ \\
\hline $\mathrm{TSP}$ & 1 & $\mathbf{0 , 4 6 5 ^ { * }}$ & 0,312 & $\mathbf{0 , 6 3 1 ^ { * * }}$ & 0,158 & $\mathbf{0 , 4 3 2 ^ { * }}$ \\
$\mathrm{As}$ & & 1 & $\mathbf{0 , 4 2 9}^{*}$ & $-0,068$ & $\mathbf{0 , 5 6 5}^{* *}$ & $-0,121$ \\
$\mathrm{Cd}$ & & & 1 & $\mathbf{0 , 6 0 4}^{* *}$ & $\mathbf{0 , 7 9 1}^{* *}$ & $\mathbf{0 , 4 4 5 ^ { * }}$ \\
$\mathrm{Mn}$ & & & & 1 & $\mathbf{0 , 4 4 4}^{*}$ & $\mathbf{0 , 4 5 3 ^ { * }}$ \\
$\mathrm{Ni}$ & & & & & 1 & 0,277 \\
$\mathrm{~Pb}$ & & & & & & 1 \\
\hline
\end{tabular}

* Correlation is significant at the 0.05 level (2-tailed)

** Correlation is significant at the 0.01 level (2-tailed)

The Principal Component Analysis is used as the extraction method and the Varimax with Kaiser Normalization, as the rotation method. The Kaiser-Meyer-Olkin (KMO) Measure of Sampling Adequacy is 0.671 (mediocre). From data of $\mathrm{As}, \mathrm{Cd}, \mathrm{Mn}, \mathrm{Ni}, \mathrm{Pb}$ and TSP daily mean values three factors can be extracted in order to explain more than $85.0 \%$ of variance. Since for these data the Bartlett's test is highly significant $(p<0.001)$, factor analysis is appropriate. The first factor, which explains $37.4 \%$ of variance, is mostly linearly correlated to $\mathrm{Pb}, \mathrm{Cd}$ and $\mathrm{Ni}$. Before 2002, the leaded fuel due to traffic was the main emission source of $\mathrm{Pb}$ to the atmosphere (Mugica et al., 2002). Except other uses, Cd sulfide is used as a curing agent in tires (IARC, 1993). Ni is found in ambient air at very low levels as a result of releases from oil and coal combustion, Ni-metal refining, sewage sludge incineration, manufacturing facilities, and other sources (WHO, 2000). Because $\mathrm{Pb}$ in the Patras air was originated from leaded petrol consumption, the first factor points out road and harbour traffic. The second factor, which explains $27.9 \%$ of variance, is mostly linearly correlated to $\mathrm{Mn}$ and TSP and the third factor, which explains $20.9 \%$ of variance, to As. Mn is a naturally occurring substance used principally in steel production. Both analyses show that As has a different origin from TSP, which are originated from traffic, re-circulated due to traffic and wind, as well as from background airborne particulate contributions. Thus, As origin should be exclusively anthropogenic and irrelevant from traffic, since As is augmented during night hours, when TSP get minimum levels. About $80 \%$ of As compounds are used in pesticides, herbicides and insecticides, while the semiconductor industry uses arsine gas, which constitutes the most toxic form of As (Cope et al., 2004). Therefore its appearance in downtown Patras should own to spray activities for disinfection of public utilities.

\section{CONCLUSIONS}

The trace mass proportions measured at the Patras sites found in the same order of those observed at several Mediterranean sites surrounded by similar activities. Only the monthly average level of As were up to 2.5 times higher than the EU yearly limit value $\left(6 \mathrm{ng} \mathrm{m}^{-3}\right)$, which means that a more systematic monitoring is required. The values measured in downtown Patras were comparable to those monitored at similar type-sites in Greek and other European cities. The value measured on the University of Patras Campus approached background levels. None pattern of toxic element proportion seems to have a good similarity to the pattern of traffic rates and the correlation of these proportions to the traffic is quite weak in general. During the typical week of October 1992, Mn levels showed the smallest fluctuations, while the levels of As presented the highest fluctuations. The loud difference between $\mathrm{Mn}$ and $\mathrm{Pb}$ levels observed during night (03:00) hours in contrast to the rest hours of the day can be explained taking into account that the leaded fuel is the Pb source, while $\mathrm{Mn}$ originates from harbour, soil re-suspension and background contributions.

The model predicting the rate of the long-term variation of $\mathrm{Pb}$ levels at the downtown Patras site may be a useful tool for epidemiological and environmental assessment studies.

According to the results of factor analysis, three factors may be extracted explaining more than $85.0 \%$ of variance. The first factor is mostly correlated to $\mathrm{Pb}, \mathrm{Cd}$ and $\mathrm{Ni}$, pointing out road and harbour traffic. The second factor is mostly correlated to Mn and TSP, indicating central heating, ship emissions, soil re-suspension and background contributions, and the third factor to As denoting 
disinfections, because the origin of As is the pesticides, herbicides and insecticides used for spray activities to disinfect buildings, warehouses and public utilities. The latter is also supported by the Spearman correlation data. The present data and conclusions may be valuable in epidemiological and environmental assessment studies for the Patras development or for other coastal cities of similar size and activities.

\section{ACKNOWLEDGEMENTS}

The authors thank A. Mourtzoukou and C. Tsianikas for conducting the airborne particulate measurements of the EEL Programs 2 and 4, correspondingly, as well as V. Bebelis, who have made the laboratory analysis of EEL Program 2. They all have fulfilled their diploma theses in the Department of Civil Engineering of the University of Patras, Greece.

\section{REFERENCES}

APHA American Public Health Association (1977) Methods of Air Sampling and Analysis, M. Katz (ed), Intersociety Committee, American Public Health Association, $2^{\text {nd }}$ edition, Washington, pp. 481-484.

Braga Marcazzan G.M. (1996) The effectiveness of PIXE approach to the study of urban and regional atmospheric pollution in Northern Italy, Nuclear Instruments and methods in Physics Research B 109/110, 429-438.

Cope G.W., Leidy R.B., Hodgon E. (2004) Classes of toxicans: use classes, A Chapter 5, Textbook of Modern Toxicology, $3^{\text {rd }}$ ed., E. Hodgon (Editor), John Wiley \& Sons, pp. 49-54.

EEA European Environment Agency (2003) European's environment: the third assessment, Environmental assessment report, No. 10, Chapter 12, EEA, Copenhagen.

Farmaki E.G., Thomaidis N.S. (2008) Current status of the metal pollution of the environment of Greece A review, Global NEST Journal, 10(3), 366-375.

HMEPPPW (Hellenic Ministry of the Environment, Physical Planning and Public Works) (2006) Checking mobile and stagnant pollution sources. Results of field tests during the year 2005, General Directorate of the Environment, Bureau of Air Pollution and Noise Control, Department of Automobiles and External Incinerations, March 2006, Athens.

HMEPPPW (Hellenic Ministry of the Environment, Physical Planning and Public Works) (2005) The air pollution in Athens, Greece. Report 2004, General Directorate of the Environment, Bureau of Air Pollution and Noise Control, Department of Air Quality, Athens.

IARC International Agency for Research on Cancer (1993) Beryllium, cadmium, mercury, and exposure in the glass manufacturing industry, IARC Monographs on the Evaluation of Carcinogenic Risks to Humans, Vol. 58, Lyons.

Karanasiou A.A., Sitaras I.E., Siskos P.A., Eleftheriadis K. (2007) Size distribution and sources of trace metals and n-alkanes in the Athens urban aerosol during summer, Atmospheric Environment, 41, 2368-2381.

Karanasiou A.A., Thomaidis N.S., Eleftheriadis K., Siskos P.A. (2005) Comparative study of pre-treatment methods for the determination of metals in atmospheric aerosol by electrothermal atomic absorption spectrometry, Talanta, 65, 1196-1202.

Kopanakis I., Lydakis-Simantiris N., Katsivela E., Pendari D., Zarmpas P., Mihalopoulos N., Lazaridis M. (2010), Global NEST Journal, 12(1), 54-62.

Manalis N., Grivas G., Protonotarios V., Moutsatsou A., Samara C., Chaloulakou A. (2005) Toxic metal content of particulate matter $\left(\mathrm{PM}_{10}\right)$, within the Greater Area of Athens, Chemosphere, 60, 557-566.

Manoli E., Voutsa D., Samara C. (2002) Chemical characterization and source identification/apportionment of fine and coarse air particles in Thessaloniki, Greece, Atmospheric Environment, 36, 949-961.

Marcazzan G.M., Valli, G. and Vecchi R. (2002) Factors influencing mass concentration and chemical composition of fine aerosols during a PM high pollution episode, The Science of the Total Environment, 298, 65-79.

Melaku S., Morris V., Raghavan D., Hosten C. (2008) Seasonal variation of heavy metals in ambient air and precipitation at a single site in Washington, DC, Environmental Pollution, 155, 88-98.

Misaelides P., Samara C., Noli F., Kouimzis Th., Anousis I. (1993) Toxic element concentrations in airborne particulate matter in the area of Thessaloniki, Greece, The Science of the Total Environment, 130/131, 139-146.

MMT (Ministry of Macedonia-Thace) (1997-2001) The air pollution in Thessaloniki, Greece; 1996, 1997, 1998, 1999, 2000. Department of Environmental Protection, Division of Air Pollution. 
Mugica V., Maubert M., Torres M., Muñoz J., Rico E. (2002) Temporal and spatial variations of metal content in TSP and $\mathrm{PM}_{10}$ in Mexico City during 1996-1998, J. Aerosol Sci, 33, 91-102.

Niedzielski P., Siepak M., Siepak J. (2002) Comparison of modifiers for determination of arsenic, antimony and selenium by atomic absorption spectrometry with atomization in graphite tube or hydride generation and in-situ preconcentration in graphite tube, Microchemical Journal, 72, 137145.

Siskos P.A., Bakeas E.B., Lioli I., Smirnioudi V.N., Koutrakis P. (2001) Chemical characterization of $\mathrm{PM}_{2.5}$ aerosols in Athens - Greece, Environmental Technology, 22, 687-695.

Skokaki G.N., Yannopoulos P.C. (2006) Lead levels in airborne particulates of Patras, Greece, and trend prediction, Fresenius Environmental Bulletin, 15, 588-595.

Thomaidis S.N., Bakeas E.B., Siskos P.A. (2003) Characterization of lead, cadmium, arsenic and nickel in $\mathrm{PM}_{2.5}$ particles in the Athens atmosphere, Greece, Chemosphere, 52, 959-966.

US EPA United States Environmental Protection Agency (1999) Integrated Risk Information System (IRIS) on Nickel Carbonyl, National Center for Environmental Assessment, Office of Research and Development, Washington, DC.

Valavanidis A., Fiotakis K., Vlahogianni Th., Bakeas E.B., Triantafillaki St., Paraskevopoulou V., Dassenakis M. (2006) Characterization of atmospheric particulates, particle-bound transition metals and polycyclic aromatic hydrocarbons of urban air in the centre of Athens (Greece), Chemosphere, 65, 760-768.

Vasilakos Ch., Pateraki S., Veros D., Maggos Th., Michopoulos J., Saraga D., Helmis C.G. (2007a) Temporal determination of heavy metals in $\mathrm{PM}_{2.5}$ aerosols in a suburban site of Athens, Greece, $J$ Atmos Chem, 57, 1-17.

Vasilakos Ch., Veros D., Michopoulos J., Maggos Th., O'Connor C.M. (2007b) Estimation of selected heavy metals and arsenic in $\mathrm{PM}_{10}$ aerosols in the ambient air of the Greater Athens Area, Greece, Journal of Hazardous Materials, 140, 389-398.

Voutsa D., Samara C., Kouimtzis Th., Ochsenkühn K. (2002) Elemental composition of airborne particulate matter in the multi-impacted urban area of Thessaloniki, Greece, Atmospheric Environment, 36, 4453-4462.

WHO World Health Organization (2000) Air Quality Guidelines for Europe. Regional Office for Europe, WHO Regional Publications, European Series $91,2^{\text {nd }}$ ed., Copenhagen.

WHO World Health Organization (2004) Manganese and its compounds: Environmental Aspects. Concise International Chemical Assessment Document 63, First draft prepared by Mr P.D. Howe, Mr H.M. Malcolm, and Dr S. Dobson, Centre for Ecology \& Hydrology, Monks Wood, United Kingdom. World Health Organization, Geneva.

Yannopoulos P.C. (2008) Long-term assessment of airborne particulate concentrations in Patras, Greece, Fresenius Environmental Bulletin, 17, 608-616.

Yannopoulos P.C., Skokaki G.N. (2003) Particulate and sulphur dioxide concentration measurements in Patras, Greece, J. Air \& Waste Manage Assoc, 53, 957-970. 